Systematic Review

\title{
Pervasiveness and Consequence of Co-Infection and Superin- fection with SARS-CoV and Mucormycosis (Black Fungus): A Systematic Review
}

\author{
Soumendra Darbar ${ }^{1, *}$, Sangita Agarwal 2,; , Srimoyee Saha ${ }^{3}$ \\ ${ }^{1}$ Research and Development Division, Dey's Medical Stores (Mfg.) Ltd., 62, Bondel Road, Kolkata-700019, \\ West Bengal, India \\ 2 Department of Applied Science, RCC Institute of Information Technology, Canal South Road, Beliaghata, \\ Kolkata-700015, India. \\ ${ }^{3}$ Faculty of Science, Jadavpur University, 188, Raja S C Mallick Road, Kolkata-700032, West Bengal, India \\ *Correspondence: dr.soumendradarbar@deysmedical.com; mailsangvee@gmail.com
}

How to cite this paper: Darbar, $\mathrm{S}$., Agarwal, S., \& Saha, S. (2021). Pervasiveness and Consequence of Co-Infection and Superin-fection with SARS-CoV and Mucormycosis (Black Fungus): A Systematic Review. Global Journal of Epidemiology and Infectious Disease, 1(1), 1-11. Retrieved from https://www.scipublications.com/journal/index.php/gjeid/article/view/69

Received: July 2, 2021

Accepted: August 11, 2021

Published: August 12, 2021

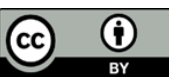

Copyright: (C) 2021 by the authors. Submitted for possible open access publication under the terms and conditions of the Creative Commons Attribution (CC BY) license (http://creativecommons.org/licenses /by/4.0/).

\begin{abstract}
Mucormycosis or black fungus although a rare fungal infection but has potential to be lethal and thus requires immediate treatment. The immune system is weakened due to SARS-CoV2 and the body becomes susceptible and vulnerable to other infections as people are immune compromised. The immune system becomes weakened due to COVID-19 treatment especially in patients who are taking steroids making the body prone to attack by black fungus. As the black fungus cases are increasing in India, the country is facing shortage in medicaments in face of dual crisis. An epidemic of black fungus is sweeping India in the wake of a severe surge in COVID-19 cases. Experts are of the opinion that the cause is a combination of factors. These factors might include contaminated oxygen equipment and use of steroid drugs to treat certain COVID-19 patients.
\end{abstract}

Keywords: Black fungus; SARS-CoV-2; fungal infections; Immune response; India

\section{Introduction}

The SARS-CoV-2 outbreak has been responsible for the health crisis all across the globe and has changed our perceptive. This biological disaster has impacted both physical and mental health along with the economic stability. Till date for management of COVID19, no direct specific pharmacological antiviral therapeutic medication is available [1]. This deadly viral infection has taken many lives throughout the globe and it is still continuing its outrage by mutating its form. The need of the hour is to develop effective and novel therapeutic medications to prevent and control the coronavirus infection. After being infected by the coronavirus the immune response is compromised and makes it difficult for the body to fight back against infection [2,3]. Various type of supportive medications are very effective to boost immune power. The role of vitamins and micronutrients including zinc, iron, selenium, magnesium, and copper in boosting the human immune system has been well established [4,5]. One of the strategies to combat the onslaught of the pandemic worldwide is mass vaccination. The Government of India has encouraged development of vaccines in multiple ways [6]. Covaxin which has been developed by Bharat Biotech in collaboration with the Indian Council of Medical Research (ICMR) and the National Institute of Virology (NIV), Pune showed efficacy of $81 \%$ according to report. Vaccination gives hope to eradicate the deadly virus permanently [7].

Mucormycosis, widely known as "Black fungus" is a diseased condition which is caused by pervasively developing moulds in dead and decaying soil and vegetation. The infected site develops necrotic black tissues and hence is named as "Black fungus" [8]. This condition has been observed synonymously among Covid-19 patients in various 
states all over the India. It is first observed in skin and also in the respiratory and nervous system by targeting the lungs and brain respectively [9]. The deadly fungus infections have been detected in Delhi, Rajasthan, Karnataka, Uttarakhand, Telangana, Madhya Pradesh, Chhattisgarh, Andhra Pradesh, Haryana, West Bengal, Uttar Pradesh and Bihar, among others. Infection is drastically increased in West Bengal. Recently 54 black fungal cases have been detected in West Bengal.

As reported by number of super speciality health providers all over India, the tissues of nose and cheeks of patients become blackened or discoloured, black lesions develop inside their mouth and vision is also blurred [10,11]. Weakened immune system, too much steroid consumption, voriconazole therapy and diabetes also put patients at greater risk of infection (Figure 1). Some doctors are of the opinion that the state of black fungus developed during home treatment of COVID patients during quarantine and when no care was taken of brining blood sugar levels under control [12].

In India up to May 27, 2021 more than 12,000 cases of the fungus have been reported as per statement of Health ministry. This potentially fatal fungal infection is likely increasing due to the surge of people with COVID-19. Fighting the coronavirus can leave people's immune systems compromised or weakened, which means they may have a higher chance of developing mucormycosis [13]. This infection is being seen in people with health issues (like COVID-19) or those who are on medications which reduce the disease fighting ability of the immune system. It commonly affects the sinuses or lungs after the fungal spores are inhaled from the air. The associated symptoms of sinus and brain mucormycosis comprise of congestion in the nasal cavity, swelling of the face, and headache [14,15]. If the infection reaches the lungs, then fever, cough and shortness of breath is observed in patients. The Indian Council of Medical Research (ICMR) has issued an advisory on the diagnosis and treatment of the disease.

\section{Causes of mucormycosis (Black fungus)}

Black fungus infection is a very rare infection and is caused when a person is exposed to mucormould. These moulds generally originate in decaying fruits and vegetables, soil, manure and plants. At times it is present in air and in nose and mucus according to the subject experts. The infection can affect the sinuses, brain and lungs. If not treated on time, it can be life-threatening. It's even dangerous for people suffering from diabetes, cancer or HIV/AIDS. The use of steroids which are used as last retort in life-saving treatment in case of moderate to serious COVID are primarily responsible for triggering Mucormycosis. Though steroids help in reducing inflammation in the lungs, it lowers the overall immune response and remarkably escalates the sugar levels in both Covid-19 patients who are diabetic or non-diabetic. This becomes a big challenge in patients who are hyperglycemic and managing the sugar level during corona virus infection becomes difficult. [16]. Scientific reports confirm the occurrence of two types of Mucormycosis namely Rhino-OrbitoCerebral Mucormycosis (ROCM) and pulmonary mucormycosis (PM) in Covid-19 patients who have recovered or discharged or infected. 


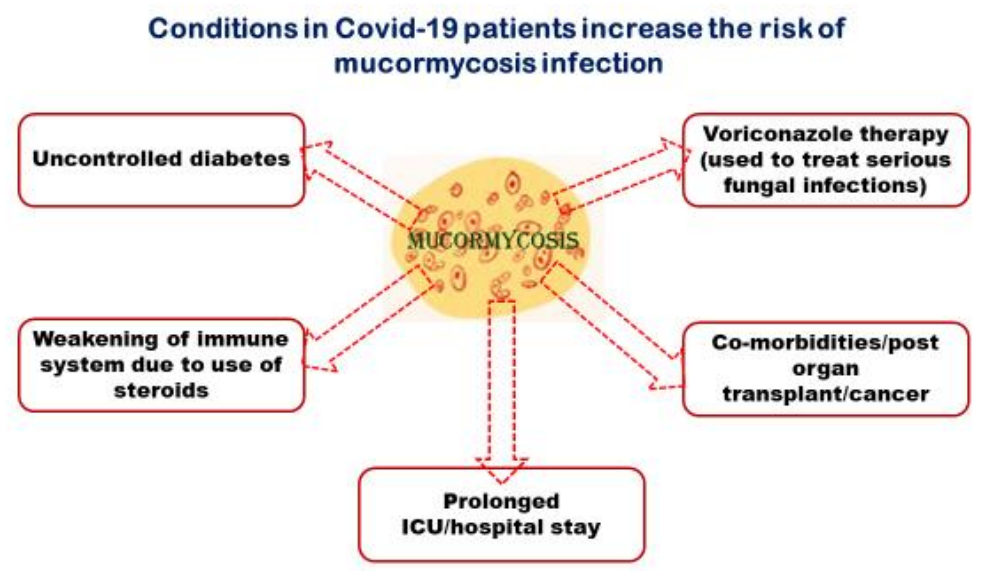

Figure 1. Conditions in Covid-19 patients increase the risk of mucormycosis infection

\section{Spread of the fungus}

Black fungus does not spread from animals to humans and is not infectious or communicable. Mostly the fungal spores are present in air and when inhaled they are attacked and destroyed by normal body's defense mechanism which is the immune system. In cases of persons who are immunocompromised, since the immunity is weak thus the moulds survive and cause infection. The risk of catching the COVID-19 virus from the feces of an infected person appears to be low.

There is some evidence that the COVID-19 virus may lead to intestinal infection and be present in feces. Approximately $2-10 \%$ of cases of confirmed COVID-19 disease presented with diarrhea [17], and two studies detected COVID-19 viral RNA fragments in the fecal matter of COVID-19.

People who fall into the following categories are more likely to develop black fungus:

- Uncontrolled diabetes, diabetic ketoacidosis, and diabetics taking steroids or tocilizumab.

- Patients taking immunosuppressant or receiving anticancer treatment, as well as those suffering from a chronic debilitating illness

- $\quad$ Patients taking high doses of steroids or tocilizumab for an extended period

- Cases of COVID-19 Severity

- Patients on oxygen who required nasal prongs, a mask, or a ventilator support

\section{Some Common Symptoms of Black Fungus Infection}

- Sinus and respiratory: This type of symptom is most common and the cavities which are involved include sinus, oral and nasal and might extend to the eyes.

- $\quad$ Skin Infections: The burnt skin or cut or scratches exposes the inner tissues to the black fungus. This results in reddening, swelling, blistering, blackening of the skin tissue and tenderness of the skin.

- Brain Infection: The black fungus infection promulgated to brain can affect the mental state of the person or lead to coma.

- Ocular infection: The black fungus infection when propagates to eyes can result in reddening and swelling of the eyes. The infection can cause eye pain; vision could be blurred and leading to blindness. In some instances, to stop the spread of infection, the eyes are required to be removed.

- Gastrointestinal Infection: The black fungus infection reaching the gastrointestinal tract can cause vomiting and nausea along with pain in the abdomen and gastrointestinal bleeding. 
The common symptoms those are commonly observed are stated in Table 1 and Figure 2.

Table1: Various common Symptoms of Black Fungus

\begin{tabular}{|c|c|}
\hline Sl. No. & Symptoms of Black Fungus \\
\hline 1. & Sinusitis - nasal blockade or congestion, nasal discharge (blackish/bloody) \\
\hline 2. & Local pain on the cheek bone, one-sided facial pain, numbness or swelling \\
\hline 3. & Blackish discoloration over bridge of nose/palate \\
\hline 4. & Loosening of teeth, jaw involvement \\
\hline 5. & Blurred or double vision with pain \\
\hline 6. & Thrombosis, necrosis, skin lesion \\
\hline 7. & Chest pain, pleural effusion, worsening of respiratory symptoms \\
\hline
\end{tabular}

\section{BLACK FUNGUS MUCORMYCOSIS SYMPTOMS}

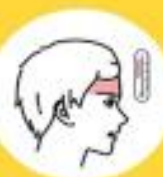

FEVER

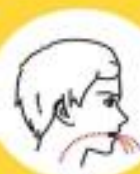

BLOODY VOMITS

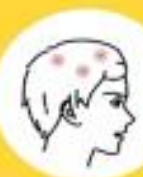

HEADACHE

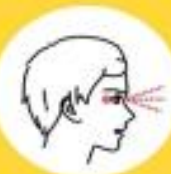

BLURRED OR DOUBLE VISION

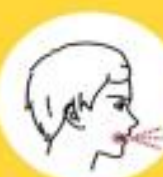

COUGHING

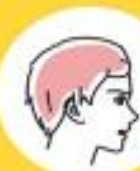

ALTERED MENTAL STATUS

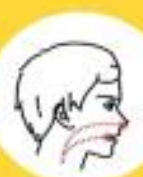

SHORTNESS OF BREATH

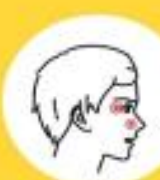

PAIN, REDNESS AROUND EYES AND/OR NOSE

Figure 2. Certain symptoms of Black fungus

\section{Covid-19 associated Mucormycosis (Black fungus)}

The black fungus infection has become more rampant because of the simultaneous outbreak of Covid-19 outbreak and this infection has become quite frequent in Covid-19 patients throughout India. When infection occurs, the patient's skin is not only affected but the brain or lungs are also susceptible to infection and many such cases has been reported in Covid-19 patients. As the black fungus infection cases are rising, the government of India has directed all states to report all cases confirmed and even suspected to the Integrated Disease Surveillance Programme. Once the COVID-19 disease occurs, the virus takes over the host machinery, it alters the internal environment and inadvertently the supportive medical treatment are somehow promoting fungal development (Figure 3). The airway mucosa and blood vessels are also impacted by COVID-19 [18] and the increase in essential mineral Iron enables the fungus to grow. The broad-spectrum antibiot- 
ics which are used as supportive treatment do not discriminate between harmful or beneficial bacteria and thus killing even the beneficial ones. Aspergillosis is prevented by using antifungal like Voriconazole but mucor persists and survives. Moreover, the longterm use of ventilators reduces the body's immunity. Long-term ventilation decreases immunity, and there is prognosis that the humidifier water used in the ventilators is responsible for the transfer of the fungus [19].

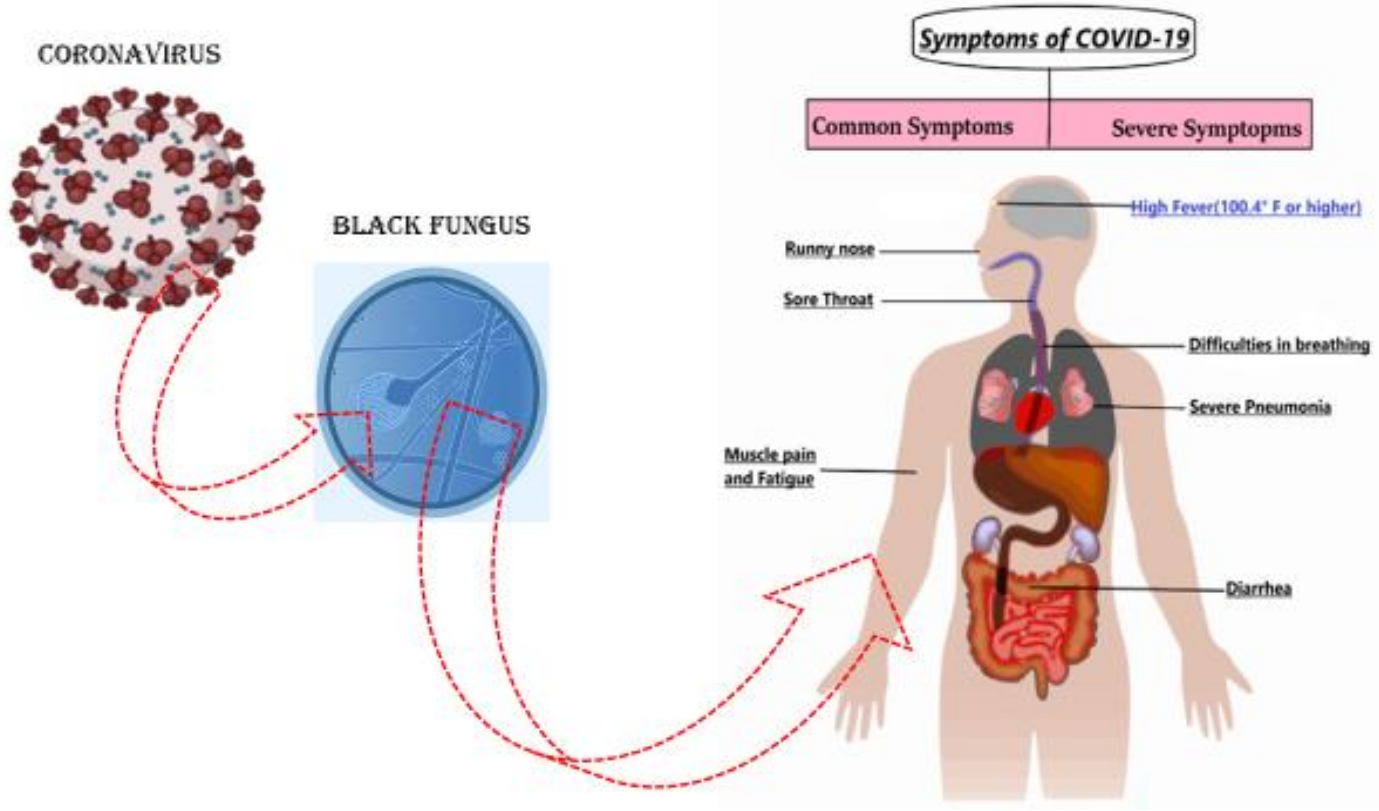

Figure 3. Covid-19 outbreak and the spread of black fungus infection.

\section{Spreading of Black fungus in India}

India has witnessed greater number of mucormycosis cases because of various factors. India is deemed as the diabetic capital of the world and presently India has estimated 77 million diabetics. Before the COVID-19 pandemic happened and in spite of a large population who were diabetic, the number of cases of mucormycosis were relatively low, but its prevalence was rising. There has been a sharp increase in mucormycosis cases since the beginning of the COVID-19 pandemic [20].

The weakened immune system because of corona virus infection makes the body susceptible to secondary infections, putting the individuals who are recovering from COVID-19 at risk of developing mucormycosis. The virus by way of its replication process, suppresses the immune system and thus the immune system is unable to fight other fungi or bacteria. As for example HIV infection leads to long-term immunity suppression but some viruses subdue the immunity for shorter duration which might be for few days or weeks during its presence. When steroids are used to treat COVID-19 patients they suppress the body's immune response which is responsible for increasing mucormycosis infection rates [21]. 


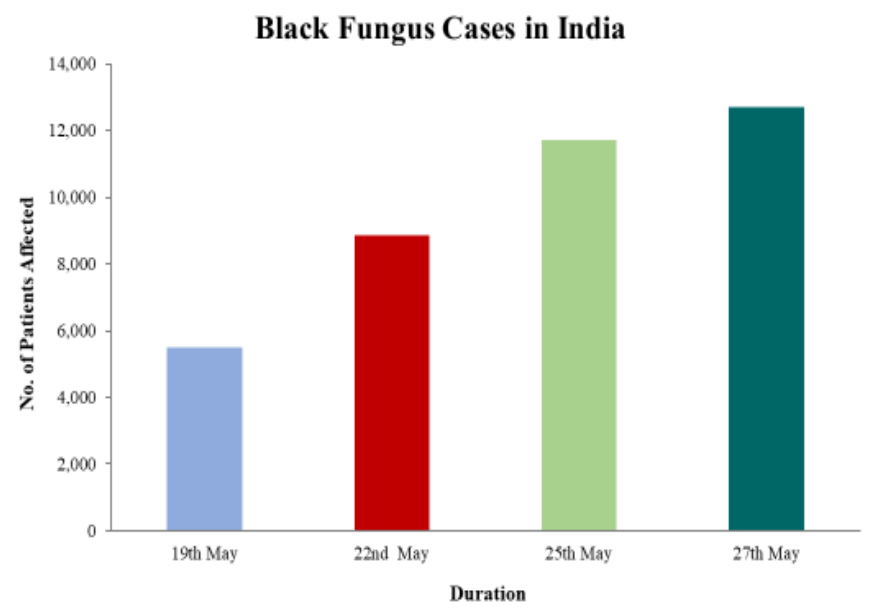

Figure 4. Number of Black fungus cases in India in May 2021

According to expert opinion the steroids are playing pivotal role in the spread of mucormycosis as they are suppressing the body's normal immune responses and allow the invasion by the fungus. Additionally, patients on oxygen support having severe COVID-19 causes the drying of the nasal cavity which is instrumental in increased risk of infection. The state of Rajasthan was the first state in the country to declare a mucormycosis epidemic on May 19, 2021. In another report from the city of Surat, 8 out of 40 COVID19 survivors who developed mucormycosis in the eye lost their eyesight. More than 1500 cases of mucormycosis, have been reported from the state of Maharashtra which resulted in 8 deaths [22]. Figure 4 shows the number of cases of Black Fungus in Month of May 2021 in India. Table 2 highlights the black fungal cases and death due to COVID-19 during the second wave in India in 2021.

Table 2. Number of black fungal cases and death due to surge of COVID-19 and its second wave in India in 2021

\begin{tabular}{|c|c|c|c|}
\hline S1. No. & States & Number of Cases & Number of Death \\
\hline 1. & Maharashtra & 1510 & 90 \\
\hline 2. & Gujarat & 1500 & - \\
\hline 3. & Telangana & 700 & 2 \\
\hline 4. & Madhya Pradesh & 573 & - \\
\hline 5. & Karnataka & 250 & - \\
\hline 6. & Delhi & 200 & 14 \\
\hline 7. & Haryana & 190 & 8 \\
\hline 8. & Uttar Pradesh & 160 & - \\
\hline 9. & Rajasthan & 100 & 2 \\
\hline 10. & Chhattisgarh & 77 & 1 \\
\hline 11. & Bihar & 56 & 2 \\
\hline 12. & Uttarakhand & 46 & 4 \\
\hline 13. & Jharkhand & 30 & 1 \\
\hline 14. & Odisha & 10 & - \\
\hline 15. & Tami Nadu & 9 & - \\
\hline 16. & Kerala & 9 & 1 \\
\hline 17. & Goa & 8 & 1 \\
\hline 18. & West Bengal & 4 & - \\
\hline 19. & Punjab & 2 & \\
\hline
\end{tabular}




\begin{tabular}{|c|c|c|c|}
\hline 20. & Assam & 1 & 1 \\
\hline 21. & Himachal Pradesh & 1 & - \\
\hline
\end{tabular}

\section{Treatment of Black fungus}

Amphotericin-B injection is the prime treatment for the treatment of this fungal infection. The injection is an antifungal medicine. If infected, the patient has to be kept under the strict supervision of eye surgeons, ENT specialists and neurosurgeons as the infection affects different parts of the body simultaneously [23].

Safety of the patient is of paramount importance and to save life in case of severe mucormycosis the infected tissues need to be surgically removed when need arises. Thereby, if the eye is affected people have lost their eyesight and in some extreme case even the upper jaw. The patients might even require an intravenous anti-fungal procedure spanning four to six weeks.

Treatment protocol are as follows:

1. The treatment of Mucormycosis needs to be immediate and aggressive. The concern is because of the fact time is very crucial to control the infection and if essential time is lost even in a presumptive diagnosis, irreversible damages are caused to the tissues of the patient.

2. Generally, all patients with the infection require medical treatment and or surgery.

3. Experts reckon that since it spreads very fast, to save lives of patient aggressive surgical debridement of the infected area is essential.

4. The role of medications in treatment of mucormycosis is vital. The objective is twin that needs to be fulfilled simultaneously: treatment with antifungal drugs to stop or slow the spread of infection and medicines to treat debilitating underlying diseases.

5. The usual choice is Amphotericin B (initially intravenous) for antifungal therapy.

6. Posaconazole or isavuconazole can treat mucormycosis.

7. Patients may even require an intravenous antifungal procedure lasting $4-6$ weeks.

8. The control of underlying diseases like diabetes need to be in optimum in patients and should be taken care.

9. The steroid treatment needs to be stopped immediately as steroids or drugs like deferoxamine (Desferal; used to remove excess iron from the body) can increase the survival of fungi in the body.

10. Additionally, some patients may require surgeries and the antifungal treatment need to be continued for an extended period (weeks to months) depending on the severity of the disease.

\section{Prevention of Black fungus}

The people having some health issues or dependent on medications owing to which there is reduction in the resistance offered by the body to combat pathogens are quite prone to Black fungus (mucormycosis) infection. The patient's immunity during and after COVID-19 treatment becomes low making them vulnerable to mucormycosis. If the patient is diabetic and develops COVID-19 disease than the chances of getting black fungal infection is increased [24,25].

Here are a list of dos and don'ts (Table 3) as per the Indian Council of Medical Research (ICMR) guidelines: 
Table 3. Dos and Don'ts to reduce the risk of Black fungus infection

\begin{tabular}{|c|c|}
\hline Dos & Don'ts \\
\hline Control high blood sugar levels & Do not overlook the symptoms of black fungus \\
\hline $\begin{array}{c}\text { Monitoring blood sugar level regularly post-re- } \\
\text { covery }\end{array}$ & $\begin{array}{c}\text { Do not take blocked nose lightly mainly after get- } \\
\text { ting recovered from COVID-19 }\end{array}$ \\
\hline $\begin{array}{c}\text { Use clean, sterile water in the humidifier for oxy- } \\
\text { gen therapy }\end{array}$ & $\begin{array}{c}\text { Do not think twice about getting done any investi- } \\
\text { gation if suggested by the doctor }\end{array}$ \\
\hline $\begin{array}{c}\text { Use steroids and antifungal medicines only when } \\
\text { prescribed by the doctor }\end{array}$ & \\
\hline
\end{tabular}

Preventive measures to be followed (Figure 5):

1. The humidifier should be regularly cleaned and replaced when Oxygen Concentrators are used.

2. The bottle containing humidifier bottle needs to be sterilized using normal saline and should be regularly refilled.

3. The face masks also need to be disinfected regularly and replaced on regular basis.

4. The person who are on steroids are required to monitor their blood glucose levels.

5. Mortified Oxygen should be used during the COVID-19 treatment.

6. The practice of good hygiene should be inculcated and also keeping the surrounding clean.

7. The daily routine of brushing and gargling can be very useful.

8. The importance of wearing mask should be advocated and practiced and the chances of getting reinfection should also be kept in might even if the person has recovered from COVID-19.

9. Regular monitoring of blood glucose levels is mandated in diabetics and should manage to keep diabetes under control.

10. The monitoring of patients is also crucial post COVID-19 infection and the use of steroids need to be reduced and drugs used for immunomodulation should be stopped. 


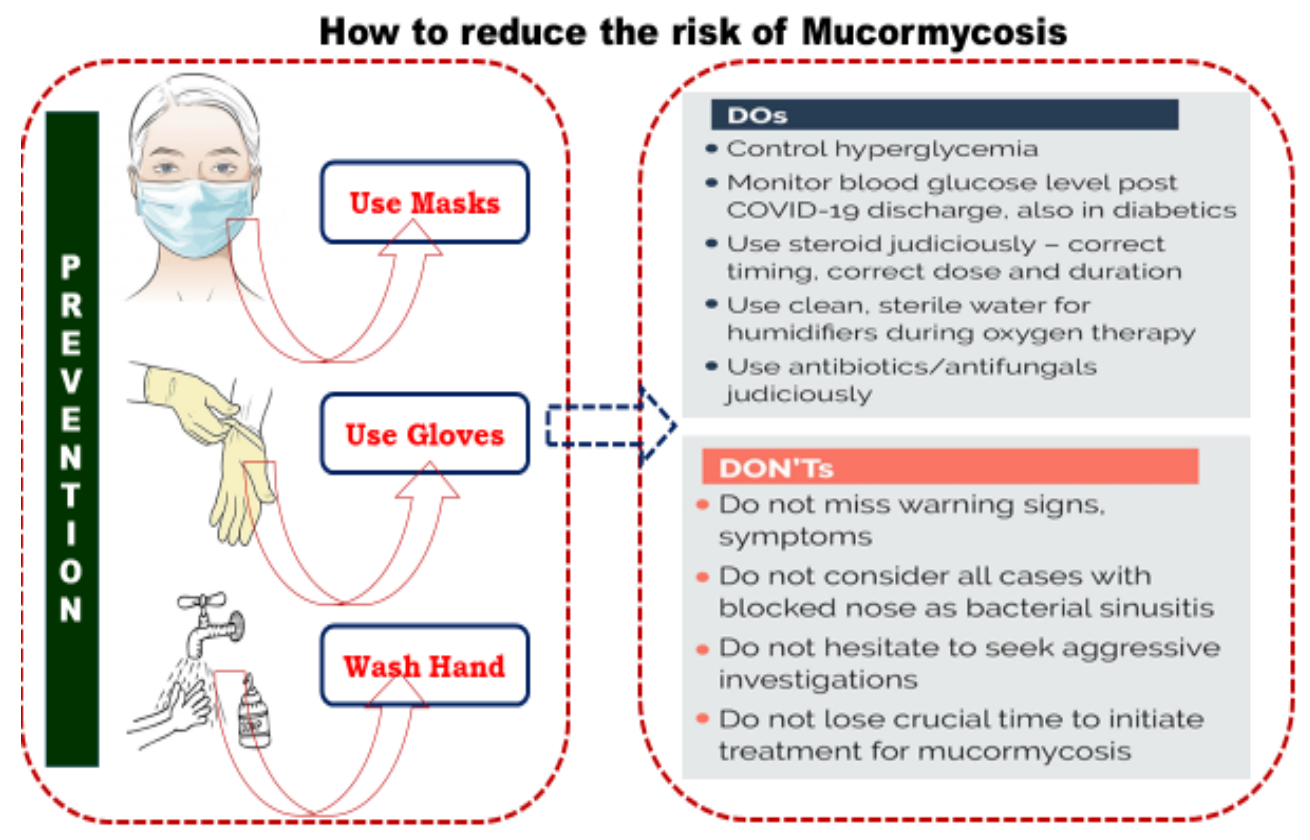

Figure 5. Prevention of Black fungus infection during COVID-19 infection

\section{Prevention of Black fungus by using Methylene Blue}

Methylene Blue (MB) has been used as an antiseptic to heal wounds for ages. Methylene Blue was initially used as an antimalarial drug and it has anti-fungal activity as it has the mechanism of redox reduction in mitochondria [26]. Currently Methylene Blue was prescribed to COVID-19 patients in sub-lingual and nebulized forms during the first wave by some doctors. Since it is quite cheap and inexpensive, cost, it was also thought to be a viable regime for developing countries like India in the treatment of symptomatic patients and as a prophylactic drug for the vulnerable population. For the treatment of methemoglobinemia, MB has been approved drug and it is fast-acting with strong antifibrotic action. COVID-19 patients show resemblance to methemoglobinemia. Silent hypoxia is caused by COVID-19 in many cases where there are no no clinical symptoms of dyspnoea but patients have low oxygen saturation (SpO2). This leads to severe cytokine storm and causing irreversible phase of respiratory distress in the patients. Given the similarities in the clinical presentations, doctors started using it. However, they stopped prescribing MB for COVID-19 treatment in absence of clinical trials and data proving the effectiveness of MB in the treatment of Covid-19. Recent clinical research stated that Methylene Blue has the mechanism to destroy mitochondria of fungus and therefore can help us in controlling mucormycosis or Black Fungus [27].

\section{Conclusion}

Fungal infections can be devastating. Mucormycosis is adding to the burden of suffering in a country already in a deep Covid-19 crisis. COVID patients those have diabetes, obesity, kidney problem, cardiac symptoms and neural complication are prone with this deadly black fungus. Commonly used drugs such as Tocilizumab and steroids and will lower the immunity of patients and use of such drugs without the supervision of a doctor will make the patient vulnerable to Covid-associated mucormycosis (CAM), loosely described as black fungal infection. It is associated with high morbidity and treatment costs. Rampant self-medication by COVID-19 patients at home without any expert supervision has become a major concern as they become vulnerable to black fungus. Proper medication and right treatment can control this dual infection. 


\section{Conflict of Interest}

The authors have no conflict of interest.

\section{Acknowledgement}

The authors are thankful to Mr. Gautam Dey, M.D. and Mr. Ranajit Dey, Jt. M.D. for facilities and encouragement during this investigation. They are also thankful to Dr. Atiskumar Chattopadhyay, Principal Secretary, Faculty Council of Science, Jadavpur University for his valuable suggestions and encouragement to conduct \& completion of the work. They are also thankful to the Management of RCCIIT for their cooperation.

\section{Author Contributions}

All authors made a significant contribution to conduct the review, whether that is in the conception, literature review, drafting, preparation of data, acquisition of data, and interpretation. After critically reviewing the article, the authors gave final approval of the version to be published; have agreed on the journal to which the essay has been submitted; and agree to be accountable for all aspects of the work.

\section{Disclosure}

The authors declare that they do not have any financial involvement. This also includes honoraria, expert testimony, employment, ownership of stocks or options, patents or grants received or pending, or royalties.

\section{Peer-review}

External peer-review was done through double-blind method.

Data and materials availability

All data associated with this study are present in the paper.

\section{References}

[1] Samad N, Sodunke TE, Abubakar AR, Jahan I, Sharma P, Islam S, Dutta S, Haque M. The implications of zinc therapy in combating the covid-19 global pandemic. Journal of Inflammation Research. 2021 Jan 1;14.

[2] Celik C, Gencay A, Ocsoy I. Can food and food supplements be deployed in the fight against the COVID 19 pandemic? BiochimicaetBiophysicaActa (BBA)-General Subjects. 2020 Nov 22:129801.

[3] Oyagbemi AA, Ajibade TO, Aboua YG, Gbadamosi IT, Adedapo AD, Aro AO, Adejumobi OA, Thamahane-Katengua E, Omobowale TO, Falayi OO, Oyagbemi TO. Potential health benefits of zinc supplementation for the management of COVID19 pandemic. Journal of Food Biochemistry. 2021 Feb;45(2): e13604.

[4] World Health Organization. WHO director-general's opening remarks at the mission briefing on COVID-19-12 March 2020; 2020. Available from: https://www.who.int/dg/speeches/ detail/who-director-general-s-opening-remarks-at-the-missionbriefing-on-covid-19-12-march-2020. Accessed October 30, 2020.

[5] Darbar S, Saha S and Agarwal S. Immunomodulatory role of vitamin C, D and E to fight against COVID-19 infection through boosting immunity: A Review II. Parana Journal of Science and Education. 2021; 7(1), 10-18.

[6] Agarwal S, Saha S, Deb T and Darbar S. Immunity augmenting food supplements for susceptible individuals in combating pandemic COVID-19 (Review) Immunity augmenting food supplements for susceptible individuals in combating pandemic COVID-19 (Review). Parana Journal of Science and Education. 2020: 6(4)79-88.

[7] DarbarS, Agarwal S and Agarwal S. “COVID19 Vaccine: COVAXIN® - India's First Indigenous Effective Weapon to Fight against Coronavirus (A Review)", Parana Journal of Science and Education. Vol. 7, No. 3, 2021, pp. 1-9.

[8] Dyer O. Covid-19: India sees record deaths as" black fungus" spreads fear. BMJ (Clinical research ed.). 2021 May 13;373: n1238.

[9] Nori P, Cowman K, Chen V, Bartash R, Szymczak W, Madaline T, Katiyar CP, Jain R, Aldrich M, Weston G, Gialanella P. Bacterial and fungal coinfections in COVID-19 patients hospitalized during the New York City pandemic surge. Infection Control \& Hospital Epidemiology. 2021 Jan;42(1):84-8.

[10] Falcone M, Tiseo G, Giordano C, Leonildi A, Menichini M, Vecchione A, Pistello M, Guarracino F, Ghiadoni L, Forfori F, Barnini S. Predictors of hospital-acquired bacterial and fungal superinfections in COVID-19: a prospective observational study. Journal of Antimicrobial Chemotherapy. 2021 Apr;76(4):1078-84.

[11] Song G, Liang G, Liu W. Fungal co-infections associated with global COVID-19 pandemic: a clinical and diagnostic perspective from China. Mycopathologia. 2020 Jul 31:1-8. 
[12] Aiyar Y, Chandru V, Chatterjee M, Desai S, Fernandez A, Gupta A, Kang G, Khanna T, Mazumdar-Shaw K, Mor N, Mukherji A. India's resurgence of COVID-19: urgent actions needed. Lancet (London, England). 2021 May 25.

[13] Imam S, Mukherjee D, Harikrishnan SN, Sinha AR. Fungus in a Viral Land-Orbital Mucormycosis in Patients With COVID-19 Infection.

[14] Sahoo JP, Mishra AP, Pradhan P, Samal KC. Misfortune Never Comes Alone-The New “Black Fungus" Accompanying COVID19 Wave. Biotica Research Today. 2021 May 14;3(5):318-20.

[15] Upasana K, Rastogi N, Thakkar D, Yadav A, Arora S, Yadav S. Mucormycosis Surge with the Second Wave of COVID-19 in India. Authorea Preprints. 2021 May 24.

[16] Chakraborty S. The epidemic of 'Black fungus' (mucormycosis) in Covid19 patients in India-a perfect synergy between immuno-suppressive drugs and supportive oxygen that promotes the bio-syntheses of ergosterol (a key component of fungal cell membranes)?.2021

[17] Nehara HR, Puri I, Singhal V, Sunil IH, Bishnoi BR, Sirohi P. Rhinocerebralmucormycosis in COVID-19 patient with diabetes a deadly trio: Case series from the north-western part of India. Indian Journal of Medical Microbiology. 2021 May 26.

[18] Pandiar D, Kumar NS, Anand R, Kamboj M, Narwal A, Shameena PM. Does COVID 19 generate a milieu for propagation of mucormycosis? Medical Hypotheses. 2021 May 26:110613.

[19] John TM, Jacob CN, Kontoyiannis DP. When uncontrolled diabetes mellitus and severe COVID-19 converge: the perfect storm for mucormycosis. Journal of Fungi. 2021 Apr;7(4):298.

[20] Veisi A, Bagheri A, Eshaghi M, Rikhtehgar MH, RezaeiKanavi M, Farjad R. Rhino-orbital mucormycosis during steroid therapy in COVID-19 patients: a case report. European Journal of Ophthalmology. 2021 Apr 10:11206721211009450.

[21] Ibrahim AS, Spellberg B, Walsh TJ, Kontoyiannis DP. Pathogenesis of mucormycosis. Clinical Infectious Diseases. 2012 Feb 1;54(suppl_1): S16-22.

[22] Gale AM, Kleitsch WP. Solitary pulmonary nodule due to phycomycosis (mucormycosis). Chest. 1972 Dec 1;62(6):752-5.

[23] Honbo S, Koga T, Yamano T, Urabe H. Treatment of Sporotrichosis and Black Fungus Infections. Japanese Journal of Medical Mycology. 1985 Sep 20;26(3):152-8.

[24] Brandt ME, Park BJ. Think fungus-prevention and control of fungal infections. Emerging infectious diseases. 2013 Oct;19(10):1688.

[25] Zhang X, Li J, Jiang C, Lin Z, Zhang Y. Review on quality and safety risk assessment and prevention measures of black fungus for export. Journal of Food Safety and Quality. 2013;4(5):1361-5.

[26] Khan S, Khan SN, Meena R, Dar AM, Pal R, Khan AU. Photoinactivation of multidrug resistant bacteria by monomeric methylene blue conjugated gold nanoparticles. Journal of Photochemistry and Photobiology B: Biology. 2017 Sep 1; 174 : $150-61$.

[27] Andreu GL. The rationale for methylene blue utility against SARS-CoV-2 infection complications. Journal of Pharmacy \&Pharmacognosy Research. 2021;9(3):379-96. 